\title{
Left Ventricular Mass in Normal Children and its Correlation with Weight, Height and Body Surface Area
}

\author{
Masa Ventricular Izquierda en Niños Normales y su Correlación \\ con el Peso, Altura y Área de Superficie Corporal
}

"Piraye Kervancioglu; ${ }^{* *}$ Mehmet Kervancioglu; ${ }^{* * *}$ M. Cudi Tuncer \& ${ }^{* * *}$ E. Savas Hatipoglu

KERVANCIOUGLU, P.; KERVANCIOGLU, M.; TUNCER, M. C. \& HATIPOGLU, E. S. Left ventricular mass in normal children and its correlation with weight, height and body surface area. Int. J. Morphol., 29(3):982-987, 2011.

SUMMARY: Echocardiographic measurement of left ventricular mass (LVM) is being used for the diagnosis of left ventricular hypertrophy in children with various cardiovascular diseases. The purposes of this study was to establish normal values of LVM according to weight, height and body surface area (BSA) in children and to determine the sex differences. We evaluated 208 children (143 males and 65 females), aged 1 day to 14 years who had no cardiovascular disease. The end-diastolic left ventricular internal dimension (LVIDd), end-diastolic left ventricular posterior wall thickness (LVPWd) and end-diastolic interventricular septum (IVSd) values were determined by M-mode echocardiographic examination. By using these values, left ventricular mass was calculated. The difference between LVIDd, LVPWd and LVM values of boys and girls were not statistically significant. We observed statistically significant differences between the sexes relative to IVSd and LVM/BSA values. The left ventricular mass and its components presented a good correlation with age, weight, height and BSA. The study let us know the lower and upper limits of cardiac dimensions and LVM obtained by echocardiography in normal Turkish children according to BSA. Also, as the LVM/BSA values show gender difference in children, sex should be taken in consideration while evaluating the left ventricular hypertrophy.

KEY WORDS: Echocardiograpy; Child; Normal values; Gender difference.

\section{INTRODUCTION}

Beginning from the embryogenesis period, right after birth, a progressive cardiac development and growth can be seen in newborn and children. In parallel with, an increase in left ventricular mass (LVM) occurs during childhood. Left ventricular mass is an important clinical measure because of its association with left ventricular hypertrophy and its significance as a strong independent risk factor for cardiovascular disease and mortality The diagnosis of an enlarged or hypertrophied heart has an important effect on the treatment of children with congenital or acquired heart disease (Malcom et al., 1993; Garner et al., 2000; Kampmann et al., 2000; Daniels et al., 1995). Echocardiography is the most commonly used non-invasive method in pediatric cardiology to understand the anatomy and function of heart for identification of congenital heart disease or exclude cardiac involvement in infectious, neuromuscular, or metabolic disorders. M mode echocardiography makes it possible to assess LVM by measuring the cardiac dimensions and wall thicknesses (Overbeek et al., 2006; Poutanen \& Jokinen, 2007). To evaluate the echocardiographic data, the values have to be compared with the normal.

The objectives of this study were to determine normal values for echocardiographic measurements in a sample of healthy children in our country, correlating them with height, weight and body surface area $\left(\mathrm{m}^{2}\right)$ and to investigate the sex differences.

\section{MATERIAL AND METHOD}

The study population consisted of 208 (143 males and 65 females) infants and children aged between one day to 15 years who were retrospectively analyzed. They were selected from the database of the Pediatric Cardiology Department of

\footnotetext{
* Anatomy Department, Gaziantep University Medical Faculty, Gaziantep, Turkey.

** Pediatric Cardiology Department, Gaziantep University Medical Faculty, Gaziantep, Turkey.

*** Anatomy Department, Dicle University Medical Faculty, Diyarbakir, Turkey.
} 
Dicle University Medical Faculty, Diyarbakir who were attended between June 2006 and June 2007. Subjects were included if they did not have cardiac disease or a history of heart involvement due to infections, neuromuscular or metabolic disorders and if they presented a normal full-term delivery with adequate weight for date and the absence of any significant illness or of mental or physical retardation. The children were referred for evaluation of a heart murmur which was found to be normal on clinical, electrocardiographic and echocardiographic examinations. The age (in months), weight (Wt) in kilograms ( $\mathrm{Kg})$, and the height $(\mathrm{Ht})$ in centimeters $(\mathrm{cm})$ were obtained. The characteristics of the subjects expressed as mean \pm SD are shown in Table I. The body surface area (BSA) in square meters $\left(\mathrm{m}^{2}\right)$ was calculated by using the DuBois \& DuBois (1916) formula as the following equation:

$\operatorname{BSA}\left(\mathrm{m}^{2}\right)=(0.0001)(71.84)(\mathrm{Wt} 0.425)(\mathrm{Ht} 0.725)$

Transthoracic echocardiographic examination was performed with the patient lying supine or in the left lateral semirecumbent position. No sedation was used during echocardiography. Twodimensional and M-mode echocardiographic studies were carried out by a single pediatric cardiologist using a commercially available machine (Philips Sonos 7500, with $2.8 \mathrm{MHz}$ transducers). The two dimensional image was used to obtain the optimum position and angulation of the M-mode line. Standard parasternal, apical, subcostal and suprasternal views were used. Enddiastole and end-systole were defined as the beginning of the QRS complex in electrocardiogram and the most thickened phase in left ventricular posterior wall, respectively. Each thickness was measured according to the recommendations of the American Society of Echocardiography (Fig. 1).

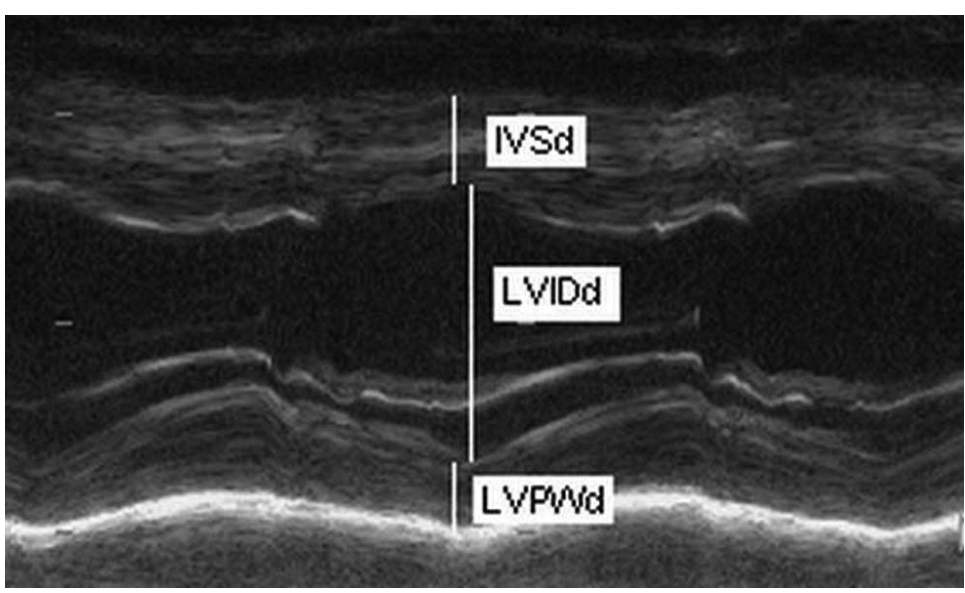

Fig. 1. M-mode echocardiographic view of left ventricular internal diameter, interventricular septum and posterior wall. IVSd, end-diastolic interventricular septum; LVIDd, end-diastolic left ventricular internal diameter; LVPWd, enddiastolic left ventricular posterior wall.

The end-diastolic left ventricular internal dimension (LVIDd), end-diastolic left ventricular posterior wall thickness (LVPWd) and end-diastolic interventricular septum (IVSd)) values were determined by echocardiographic examination. Left ventricular mass was calculated by the formula of Devereux et al. (1986) which has been validated for use in children with normal hearts:

\section{LVM $(\mathrm{g})=0.8\{1.04((\mathrm{IVST}+\mathrm{LVID}+\mathrm{LVPWT}) 3-\mathrm{LVID} 3)\}+0.6$}

The children were divided into 6 groups according to their BSA: $0.20-0.25 \mathrm{~m}^{2}, 0.25-0.50 \mathrm{~m}^{2}, 0.50-0.75 \mathrm{~m}^{2}, 0.75-1.0 \mathrm{~m}^{2}, 1.0-1.25 \mathrm{~m}^{2}$, and $1.25-1.50 \mathrm{~m}^{2}$. The means, \pm SD of LVIDd, LVPWd, IVSd, LVM and LVM/BSA values were estimated for all groups (Table II).

Table I. Summary of the clinical characteristics and echocardiographic measurements of total of the children studied (T), and individually per male (M) and female (F). Data are expressed as mean \pm standard deviation. BSA, body surface area; IVSd, end-diastolic interventricular septum; LVIDd, end-diastolic left ventricular internal diameter; LVPWd, end-diastolic left ventricular posterior wall; LVM, left ventricular mass; LVM/BSA, left ventricular mass/body surface area.

\begin{tabular}{lcccc}
\hline & $\mathrm{T}(\mathrm{n}=208)$ & $\mathrm{M}(\mathrm{n}=143)$ & $\mathrm{F}(\mathrm{n}=65)$ & Significance $p$ values \\
\hline Age $(\mathrm{months})$ & $77.13 \pm 50,84$ & $77.13 \pm 51.71$ & $77.14 \pm 49.26$ & $<0.05$ \\
Weight $(\mathrm{Kg})$ & $22.68 \pm 11.80$ & $22.72 \pm 11.80$ & $22.60 \pm 11.89$ & $<0.05$ \\
Height $(\mathrm{cm})$ & $112.25 \pm 30.27$ & $112.33 \pm 30.75$ & $112.09 \pm 29.43$ & $<0.05$ \\
BSA $\left(\mathrm{m}^{2}\right)$ & $0.83 \pm 0.34$ & $0.83 \pm 0.35$ & $0.83 \pm 0.34$ & $<0.05$ \\
IVSd $(\mathrm{cm})$ & $0.62 \pm 0.14$ & $0.63 \pm 0.14$ & $0.59 \pm 0.14$ & $=0.032$ \\
LVIDd $(\mathrm{cm})$ & $3.19 \pm 0.70$ & $3.22 \pm 0.70$ & $3.12 \pm 0.70$ & $<0.05$ \\
LVPWd $(\mathrm{cm})$ & $0.56 \pm 0.13$ & $0.56 \pm 0.13$ & $0.54 \pm 0.12$ & $<0.05$ \\
LVM $(\mathrm{g})$ & $47.00 \pm 23.05$ & $48.85 \pm 23.92$ & $42.95 \pm 20.59$ & $<0.05$ \\
LVM/BSA $(\mathrm{g} / \mathrm{m} 2)$ & $55.56 \pm 15.09$ & $57.88 \pm 15.90$ & $50.43 \pm 11.70$ & $=0.001$ \\
\hline
\end{tabular}


Statistical analysis and the calculations were performed using SPSS for Windows, version 17.0. The strength of the associations between echocardiographic measurements and age, weight and BSA was assessed using Pearson's correlation coefficient ( $\mathrm{r}$ value). Differences between means of males and females were assessed with Student's $t$ test. Ap value of $<0.05$ was considered significant.

\section{RESULTS}

There were no statistically significant differences between the age ( $p>0.05)$, weight $(p>0.05)$, height $(p>0.05)$ and the BSA $(p>0.05)$ of the sexes. Their heights and weights were all within the normal range on standard growth chart.
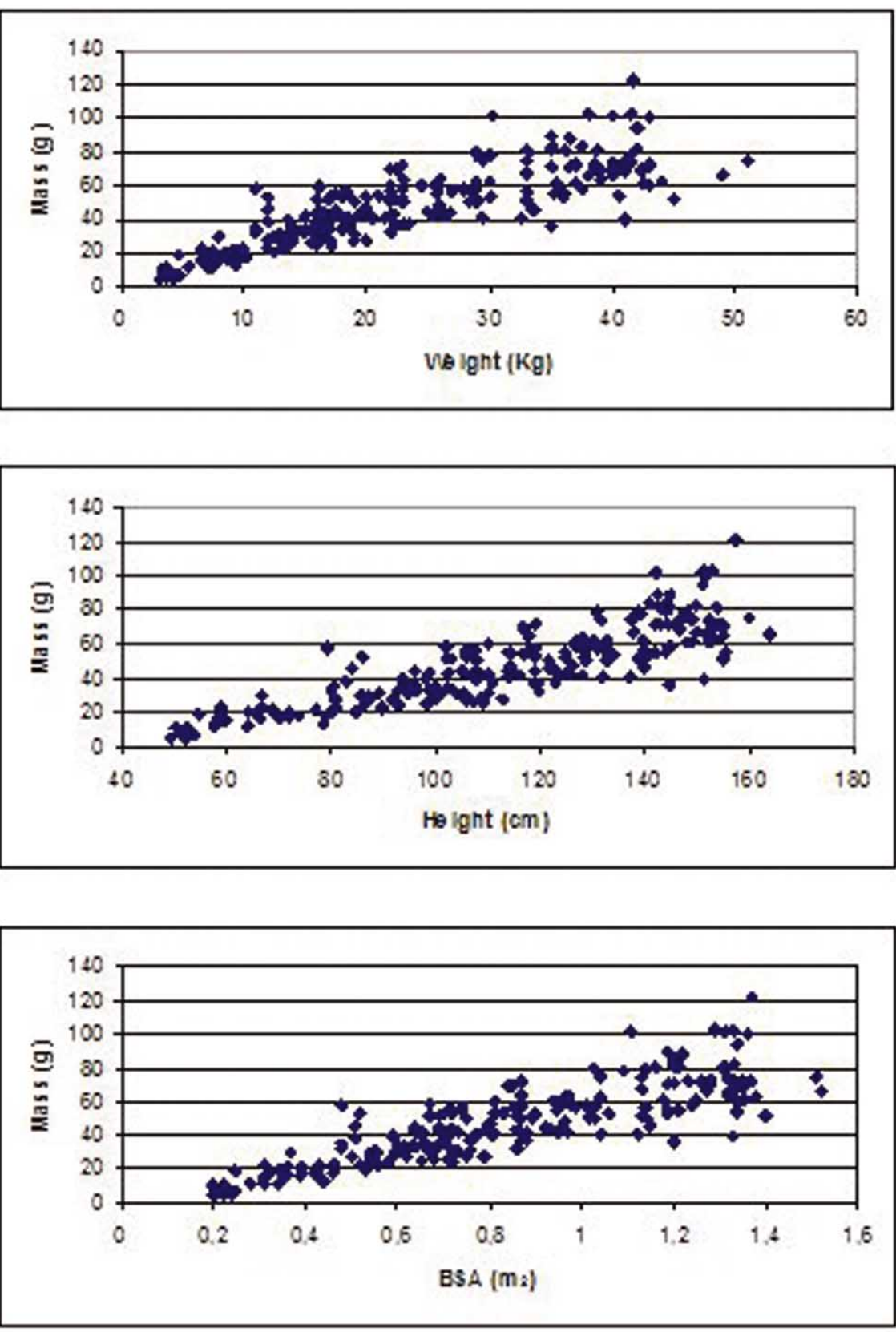

Fig. 2. The relationship between the left ventricular mass and weight, height and body surface area (BSA)
Table I presents the mean \pm standard deviations relative to age, weight, height, BSA and echocardiographic measurements and those of their derivatives. It also presents these variables relative to sex. There were no significant differences in LVIDd, LVPWd and LVM values between the sexes. We observed statistically significant differences between the sexes relative to IVSd ( $\mathrm{p}=0.032$ ). IVS thicknesses were greater in boys than girls. Although, LVM ( $\mathrm{p}=0.071)$ estimates tend to be greater in boys than girls, the statistical significance was achieved only in the values of LVM/ BSA $(p=0.001)$. We analyzed the children with the BSA above one square meter, the results were same.

The end-diastolic left ventricular internal dimension, LVPWd, IVSd, LVM and LVM/BSA values presented a good correlation with age, weight, height and BSA. The relationship between the LVM and weight, height and BSA appears in Fig. 2. Table III presents the values of Pearson's correlation coefficients of echocardiographic measurements relative to age, weight, height and BSA of all the children studied and according to sex. Pearson's correlation coefficients between the values of echocardiographic measurements and age, weight, height, BSA and sex did not present statistically significant differences.

The means, \pm SD values of LVIDd, LVPWd, IVSd, LVM and LVM/BSA relative to the BSA groups were established in Table II. 
Table II. Means and standard deviations of IVSd, end-diastolic interventricular septum; LVIDd, end-diastolic left ventricular internal diameter; LVPWd, end-diastolic left ventricular posterior wall; LVM, left ventricular mass; LVM/BSA, left ventricular mass/body surface area of the normal children according to the body surface area (BSA) groups.

\begin{tabular}{lcccccc}
\hline BSA $\left(\mathrm{m}^{2}\right)$ Groups & $\mathrm{n}$ & IVSd $(\mathrm{mm})$ & LVIDd $(\mathrm{mm})$ & LVPWd $(\mathrm{mm})$ & LVM $(\mathrm{g})$ & LVM/BSA $\left(\mathrm{g} / \mathrm{m}^{2}\right)$ \\
\hline $0.20-0.25$ & 13 & $0.37 \pm 0.07$ & $1.62 \pm 0.24$ & $0.34 \pm 0.05$ & $8.11 \pm 3.89$ & $35.82 \pm 15.27$ \\
$0.26-0.50$ & 26 & $0.50 \pm 0.11$ & $2.40 \pm 0.38$ & $0.45 \pm 0.08$ & $21.54 \pm 9.41$ & $54.04 \pm 18.51$ \\
$0.51-0.75$ & 54 & $0.58 \pm 0.10$ & $3.06 \pm 0.38$ & $0.51 \pm 0.09$ & $37.05 \pm 10.11$ & $57.72 \pm 14.84$ \\
$0.76-1.00$ & 43 & $0.65 \pm 0.10$ & $3.33 \pm 0.31$ & $0.59 \pm 0.10$ & $50.44 \pm 11.19$ & $57.75 \pm 12.47$ \\
$1.01-1.25$ & 40 & $0.71 \pm 0.10$ & $3.66 \pm 0.39$ & $0.63 \pm 0.11$ & $64.68 \pm 15.26$ & $57.29 \pm 12.89$ \\
$1.26-1.50$ & 32 & $0.70 \pm 0.12$ & $3.95 \pm 0.39$ & $0.67 \pm 0.11$ & $75.20 \pm 17.05$ & $56.45 \pm 13.21$ \\
\hline
\end{tabular}

Table III. r values of Pearson's correlation coefficients of echocardiographic measurements relative to age, weight, height and body surface area (BSA) of total of the children studied (T), and individually per male (M) and female (F). IVSd, end-diastolic interventricular septum; LVIDd, end-diastolic left ventricular internal diameter; LVPWd, end-diastolic left ventricular posterior wall; LVM, left ventricular mass; LVM/BSA, left ventricular mass/body surface area.

\begin{tabular}{lcccccccccccc}
\hline Echocardiographic & \multicolumn{3}{c}{ Age } & \multicolumn{3}{c}{ Weight } & \multicolumn{3}{c}{ Height } & \multicolumn{3}{c}{ BSA } \\
\cline { 2 - 12 } measurements & T & M & F & T & M & F & T & M & F & T & M & F \\
\hline IVSd & 0.62 & 0.61 & 0.66 & 0.61 & 0.60 & 0.67 & 0.66 & 0.64 & 0.73 & 0.64 & 0.62 & 0.70 \\
LVIDd & 0.83 & 0.83 & 0.83 & 0.81 & 0.81 & 0.81 & 0.86 & 0.86 & 0.87 & 0.84 & 0.84 & 0.85 \\
LVPWd & 0.63 & 0.64 & 0.63 & 0.63 & 0.63 & 0.64 & 0.65 & 0.65 & 0.66 & 0.65 & 0.64 & 0.66 \\
LVM & 0.85 & 0.85 & 0.89 & 0.84 & 0.84 & 0,88 & 0.86 & 0.85 & 0.89 & 0.86 & 0.85 & 0.90 \\
LVM/BSA & 0.16 & 0.13 & 0.28 & 0.14 & 0.10 & 0.27 & 0.19 & 0.15 & 0.35 & 0.17 & 0.13 & 0.31 \\
\hline
\end{tabular}

\section{DISCUSSION}

Echocardiography is a non-invasive and a confident method in the diagnosis of congenital and acquired heart disease. M-mode echocardiography is used most widely to measure left ventricular mass because of its wide availability, moderate expense, anatomic and prognostic validation (Rogé et al., 1978; Devereux et al.). As, increased LVM has been established as a strong independent risk factor for cardiovascular morbidity (eg., arrhythmia, congestive heart failure, and myocardial infarction) and mortality, for management of the treatment and evaluation of the prognosis, the normal values of LVM are also needed (Levy et al., 1987; Epstein et al., 1975). In the 1970s, several studies established the normal limits of $\mathrm{M}$ - mode echocardiographic measurements in infants and children (Epstein et al.; Allen et al., 1977; Lundström, 1974). Henry et al. (1980) studied with 105 normal subjects ranging from one day to 23 years of age. They found that echocardiographic measurements of the internal dimensions, thicknesses and mass of the chambers of the heart follow a linear regression upon one of three functions, (direct linear, square root, cube root) of the BSA. There is no agreement in the literature about the anthropometric parameter which presents the best correlation with the echocardiographic measurements. Some studies show a better correlation with BSA, some of them with weight and others with height (Huwez et al., 1994; de Simone et al., 1992; Dai et al., 2009). Bonatto et al. (2006) reported that for normal children there is no difference whether they correlate the values of cardiac measurements assessed by echocardiography with age, weight, height or BSA. Epstein et al. suggested that plotting the echocardiographic measurements against the age is not logical as all age range has a wide body size spectrum. So they chose body surface area to standardize the echocardiographic data of their study. In the present study, no significant differences were observed between the values of Pearson's correlation coefficients when the values of echocardiographic measurements studied were correlated with age, weight, height and BSA. As the recent studies used BSA to relate their data, we preferred to group the children according to BSA as it is an independent variable.

It was suggested that the number of human cardiac myocytes is determined within the first year after birth, when mitotic activity of cardiocytes appears to cease. So, subsequent increases in LVM reflect cellular enlargement (hypertrophy) (de Simone et al., 1995). According to the studies in the normal adults, LVM is larger in men than in women (Levy et al., 1987; de Simone et al., 1992). de Simone et al. (1995) stated that this difference might be due to a gender difference in the number of myocytes that was 
programmed in early life or a hypertrophy of myocytes during development in males, else both of them. In order to search this difference, de Simone et al. (1995) compared LVM in 333 female and 278 male normal subjects from 4 months to 70 years of age. They found no statistical difference in LVM values between boys and girls before age 12 years and suggested that the initial number of cardiac myocytes is likely to be similar in males and in females. However, in all older ages, they found that LVM in men was $25 \%$ to $38 \%$ greater than that in women which was statistically significant. Lester et al. (1987) studied 202 (125 male, 77 female) North American subjects from 25 days to 23 years of age. The authors observed that the values of echocardiographic measurements were significantly higher for male children, when the BSA was above one square meter. Bonatto et al. analyzed the values of echocardiographic datas according to sex and found significant difference relative to LVM, with higher values for male children. Nagasawa \& Arakaki (2002) assessed the thickness of the normal left ventricular wall of 251 (128 male, 123 female) Japanese children, aged between one month and 18 years. The authors reported that the values of left ventricular wall thicknesses were significantly higher in male children. Kapmann et al. studied 2036 healthy infants and children in central Europe and found no significant differences in echocardiographic values between the sexes. They thought that the reason for this might be that, as there have been six different pediatric cardiologists examining the children, a small sex difference could have been within the range of interobserver variability. In another study, Goble $e t$ al. (1992) found that LVM and LVM/BSA were significantly different between boys and girls. They also found that each of the variables which have been used in the equation to calculate LV mass was significantly larger in the boys except for septal thickness. Poutanen \& Jokinen stated that in adolescents and young adult males had higher LVM/BSA than females. In the present study, although boys have about $10 \%$ higher LVM than girls, the difference was not significant relative to sex. We found significant difference between only IVSd and LVM/BSA values of the sexes. We analyzed the children with the BSA above one square meter, the results were same.

In conclusion, as there is a strong relation between increased LVM and cardiovascular disease, it is important to measure the components of LVM and to evaluate LVM accurately. The results established according to BSA in this study contribute to determination of the lower and upper limits of cardiac dimensions and LVM obtained by echocardiography in normal Turkish children. Also, LVM/ BSA values show statistically significant difference between sexes, indicating that, in children, gender should be taken in the consideration while echocardiographic measurements are analyzed.

KERVANCIOUGLU, P.; KERVANCIOGLU, M.; TUNCER, M. C. \& HATIPOGLU, E. S. Masa ventricular izquierda en niños normales y su correlación con el peso, altura y área de superficie corporal. Int. J. Morphol., 29(3):982-987, 2011.

RESUMEN: La medición ecocardiográfica de la masa ventricular izquierda (LVM) se utiliza para el diagnóstico de la hipertrofia ventricular izquierda en los niños con diversas enfermedades cardiovasculares. Los objetivos de este estudio fueron establecer los valores normales de MVI en función del peso, altura y área de superficie corporal (BSA) en niños y determinar las diferencias entre sexos. Se evaluaron 208 niños (143 varones y 65 mujeres), con edades entre 1 día a 14 años de edad que presentaban enfermedades cardiovasculares. Se determinaron los valores interno al final del diástole ventricular izquierdo (LVIDd), el espesor de la pared posterior (LVPWd) y el tabique interventricular (IVSd) mediante el examen ecocardiográfico en modo M. Utilizando estos valores, fue calculada la masa ventricular izquierda. Las diferencias de los valores LVIDd, LVPWd LVM entre niños y niñas no fueron estadísticamente significativas. Observamos diferencias estadísticamente significativas entre los sexos en relación con los valores IVSd y LVM/BSA. La masa ventricular izquierda y sus componentes presentaron una buena correlación con la edad, peso, altura y BSA. Este estudio nos permitió conocer los límites superior e inferior de las dimensiones cardíacas, junto a la LVM obtenidas mediante ecocardiografía en niños turcos normales de acuerdo con el BSA. Además, como los valores LVM/BSA muestran diferencias entre sexos en los niños, el sexo se debería tomar en consideración al evaluar la hipertrofia ventricular izquierda.

PALABRAS CLAVE: Ecocardiografía; Niño; Valores normales; Diferencia de sexo.

\section{REFERENCES}

Allen, H. D.; Goldberg, S. T.; Sahn, D. J.; Schy, N. \& Wojcik, R. A quantitative echocardiographic study of champion childhood swimmers. Circulation, 55(1):142-5,1977.

Bonatto, R. C.; Fioretto, J. R.; Okoshi, K.; Matsubara, B. B.;
Padovani, C. R.; Manfrin, T. C.; Gobbi, M. de F.; Martino, R. S. \& Bregagnollo, E. A. Percentile curves of normal values of echocardiographic measurements in normal children from the Central-Southern region of the state of São Paulo, Brazil. Arq. Bras. Cardiol., 87(6):711-21, 2006. 
Dai, S.; Harrist, R. B.; Rosenthal, G. L. \& Labarthe D. R. Effects of body size and body fatness on left ventricular mass in children and adolescents. Am. J. Prev. Med., 37(1 Suppl): 97-104, 2009.

Daniels, S. R.; Kimball, T. R.; Morrison, J. A.; Khoury, P.; Witt, S. \& Meyer, R. A. Effect of lean body mass, fat mass, blood pressure, and sexual maturation on left ventricular mass in children and adolescents. Circulation, 92(11):3249-54, 1995.

de Simone, G.; Daniels, S. R.; Devereux, R. B.; Meyer, R. A.; Roman, M. J.; De Vittis, O. \& Alderman, M. H. Left ventricular mass and body size in normotensive children and adults: Assessment of allometric relations and impact of overweight. J. Am. Coll. Cardiol., 20(5):1251-60, 1992.

de Simone, G.; Devereux, R. B.; Daniels, S. R. \& Meyer, R. A. Gender differences in left ventricular growth. Hypertension, 26(6 Pt 1):979-83, 1995.

Devereux, R. B.; Alonso, D. R.; Lutas, E. M.; Gottlieb, G. J.; Campo, E.; Sachs, I. \& Reichek, N. Echocardiographic assessment of left ventricular hypertrophy: comparison to necropsy findings. Am. J. Cardiol., 57(6):450-8, 1986.

Du Bois, D. \& Du Bois, E. F. A formula to estimate the approximate surface area if height and weight be known. Nutrition, 5(5):303-11, 1989.

Epstein, M. L.; Goldberg, S. T.; Allen, H. D.; Konecke, L. \& Wood, J. Great vessel, cardiac chamber and wall growth patterns in normal children. Circulation, 51(6):1124-9, 1975.

Garner, C.; Lecomte, E.; Visvikis, S.; Abergel, E.; Lathrop, M. $\&$ Soubrier, F. Genetic and enviromental influences on left ventricular mass. A family study. Hypertension, 36(5):7406, 2000 .

Goble, M. M.; Mosteller, M.; Moskowitz, W. B. \& Schieken, R. M. Sex differences in the determinants of left ventricular mass in childhood. The Medical College of Virginia Twin Study. Circulation, 85(5):1661-5, 1992.

Henry, W. L.; Gardin, J. M. \& Ware, J. H. Echocardiographic measurements in normal subjects from infancy to old age. Circulation, 62(5):1054-61, 1980.

Huwez, F. U.; Houston, A. B.; Watson, J.; McLaughlin, S. \& Macfarlane, P. W. Age and body surface area related to normal upper and lower limits of M mode echocardiographic measurements and left ventricular volume and mass from infancy to early adulthood. Br. Heart. J., 72(3):276-80, 1994.

Kampmann, C.; Wiethoff, C. M.; Wenzel, A.; Stolz, G.; Betancor, M.; Wippermann, C. F.; Huth, R. G.; Habermehl, P.; Knuf, M.; Emschermann. T. \& Stopfkuchen, H. Normal values of
M mode echocardiographic measurements of more than 2000 healthy infants and children in central Europe. Heart, 83(6):667-72, 2000.

Lester, L. A.; Sodt, P. C. \& Hutcheon, N. \& Arcilla, R. A. Mmode echocardiography in normal children and adolescents: some new perspectives. Pediatr. Cardiol., 8(1):27-33, 1987.

Levy, D.; Savage, D. D.; Garrison, R. J.; Anderson, K. M.; Kannel, W. B. \& Castelli, W. P. Echocardiographic criteria for left ventricular hypertrophy: the Framingham Heart Study. Am. J. Cardiol., 59(9):956-60, 1987.

Lundström, N. R. Clinical applications of echocardiography in infants and children. I. Investigation of infants and children without heart disease. Acta Paediatr. Scand., 63(1):23-32, 1974.

Malcom, D. D.; Burns, T. L.; Mahoney, L. T. \& Lauer, R. M. Factors affecting left ventricular mass in childhood: the Muscatine Study. Pediatrics, 92(5):703-9, 1993.

Nagasawa, H. \& Arakaki, Y. Identification of gender differences in the thickness of the left ventricular wall by echocardiography in children. Cardiol. Young., 12(1):3743, 2002.

Overbeek, L. I.; Kaputsa, L.; Peer, P. G.; de Korte, C. L.; Thijssen, J. M. \& Daniels, O. New reference values for echocardiographic dimensions of healthy Dutch children. Eur. J. Echocardiogr., 7(2):113-21, 2006.

Poutanen, T. \& Jokinen, E. Left Ventricular Mass in 169 Healthy Children and Young Adults Assessed by Three-Dimensional Echocardiography. Pediatr. Cardiol., 28(3):201-7, 2007.

Rogé, C. L.; Silverman, N. H.; Hart, P. A. \& Ray, R. M. Cardiac structure growth pattern determined by echocardiography. Circulation, 57(2):285-90, 1978.

\section{Correspondence to: \\ Piraye Kervancioglu \\ Department of Anatomy \\ The University of Gaziantep \\ Medical Faculty \\ University Avenue 27310 \\ Sehitkamil / Gaziantep \\ TURKEY}

Tel: +905057769756

Fax: +903423601617

Email: pkervancioglu@gantep.edu.tr pirayek@hotmail.com

Received: 19-02-2011

Accepted: 08-04-2011 